\title{
Rudimentos históricos do associativismo e do sindicalismo dos trabalhadores em educação no Estado de São Paulo (1978-2017)
}

\section{The historical roots of workers "education associations and unions in the State of São Paulo (1978-2017)}

Carlos Bauer Professor Titular do Departamento de Educação e do Programa de Pós-Graduação em Educação (PPGE) Universidade Nove de Julho (UNINOVE) Embu-Guaçu, São Paulo - Brasil carlosbauer@uni9.pro.br

(D) Julián Gindin Professor da Faculdade de Educação da Universidade Federal Fluminense (UFF) Universidade Federal Fluminense - UFF Niterói, Rio de Janeiro - Brasil julian_gindin@hotmail.com

Resumo: Em Rudimentos históricos do associativismo e do sindicalismo dos trabalhadores em educação no Estado de São Paulo procuramos trazer um amplo mapeamento da organização dos trabalhadores em educação paulistas, tendo como base uma periodização iniciada com o ciclo das greves de 1978, se estendendo até o ano de 2017, momento este marcado por uma reforma trabalhista que alterou drasticamente a legislação que vigorava desde os idos das décadas de 1930-40. Houve ainda a preocupação de incluir os segmentos menos estudos ou pouco considerados nas pesquisas sobre esta temática na área da educação, como é o caso dos professores universitários, os docentes do ensino privado e os trabalhadores técnicos administrativos do sistema educativo.

Palavras-chave: associativismo; história da educação; São Paulo; sindicalismo.

Abstract: In "The historical roots of workers `education associations and unions in the State of São Paulo" (1978-2017)", we seek to bring a wide mapping of the workers' education organizations in São Paulo. We started with the strike cycle that begun in 1978 and we concluded on the year of 2017, when was sanction a labor law that drastically altered the legislation in force since the 1930s-40s. We were also concerned to include less studied segments from the workers' education organizations -as is the case of university professors, private education teachers and administrative workers of the education system.

Key-words: workers' associations; history of education; São Paulo; unionism.

Cite como

(ABNT NBR 6023:2018)

BAUER, Carlos; GINDIN, Julián. Rudimentos históricos do associativismo e do sindicalismo dos trabalhadores em educação no Estado de São Paulo (1978-2017). Dialogia, São Paulo, n. 37, p. 1-22, e19686, jan./abr. 2021. Disponível em: https://doi.org/10.5585/dialogia.n37.19686.

American Psychological Association (APA)

Bauer, C., \& Gindin, Julián. (2021, jan./abr.). Rudimentos históricos do associativismo e do sindicalismo dos trabalhadores em educação no Estado de São Paulo (1978-2017). Dialogia, São Paulo, 37, p. 1-22, e19686. https://doi.org/10.5585/dialogia.n37.19686. 


\section{Introdução}

Os trabalhadores em educação, no Brasil, são representados por diferentes organizações, constituindo uma verdadeira constelação de siglas. Em termos gerais, pode-se dizer que o projeto de criar organizações únicas por estado que representem todos os trabalhadores em educação das redes estaduais e municipais de educação do setor básico, embora lograsse avanços, também encontrou fortes limites (particularmente no caso das redes municipais). No ensino superior do setor público houve, num primeiro momento, a criação e, depois, a unificação das diferentes associações locais. No setor privado, nas últimas décadas, há um crescimento da quantidade de sindicatos - o que decorre da organização de setores não instituídos formalmente e da divisão de sindicatos.

No Estado de São Paulo, atualmente, há uma miríade de entidades representativas de professores, diretores, supervisores, funcionários etc.; do nível básico e superior, do setor público, confessional e privado, municipais, estaduais e federais.

O objetivo do presente texto é o de traçar uma cartografia histórica do movimento associativo e sindical dos trabalhadores em educação no estado de São Paulo, desde finais da década de 1970 até o ano de 2017, analisando a tensão entre as tendências unificadoras e fragmentadoras presentes no movimento sindical docente no Brasil.

No campo acadêmico educacional, as visões mais reducionistas ou formalistas, endereçam suas mais sinceras críticas, aos estudos relacionados às formas organizativas que são próprias dos que vivem do próprio trabalho no mundo do capital, argumentado que o sindicalismo docente, não é problematizado no contexto do debate educacional, mas, sim, como próprio das instituições que merecem atenção, por exemplo, da ciência política ou mesmo da sociologia.

Desta forma, mesmo que de forma inadvertida, acabam se furtando de considerar que a defesa dos direitos históricos, como é caso da universalização do ensino público, laico e gratuito para todos, a luta pelo atendimento das reivindicações corporativas e das necessidades imediatas da reprodução da própria existência física e material dos professores se operam como condição sine qua non para o desenvolvimento ulterior de quaisquer propostas pedagógicas e possibilidades de intervenção qualificada dos trabalhadores da educação que atuam na sociedade burguesa.

Os subsídios que tornaram possível esses escritos foram reunidos pelos pesquisadores do Grupo de História e Teoria da Profissão Docente e do Educador Social (Gruphis), do Programa de Pós-Graduação em Educação (PPGE), da Universidade Nove de Julho (UNINOVE), na realização da Cartografia do associativismo e do sindicalismo dos trabalhadores em educação no Brasil, sob a coordenação dos professores Carin Sanches de Moraes, Cássio Diniz, Hélida Lança e 
Carlos Bauer. Também é importante mencionar e agradecer a professora Maria C. Bandeira que cuidou da revisão dos originais.

Ao longo dessas linhas dialogamos com as preocupações de Sadi Dal Rosso, particularmente, com o seu artigo seminal intitulado "Fragmentação sindical" publicado em 2013. O argumento deste autor é que a classe trabalhadora se define pela sua generalidade, enquanto os sindicatos pela particularidade de cada categoria.

Neste contexto, o que se mostrou dominante foi à tendência à fragmentação, a partir, por exemplo, entre outras coisas: da criação de novos municípios (o que admite a criação de novos sindicatos); das diferenças políticas dentro do movimento sindical (que estimula o surgimento de organizações alternativas); das mudanças tecnológicas associadas que atenderam ao vertiginoso crescimento do ensino a distância, que permitiu a expansão de novos segmentos de trabalhadores em educação, os monitores, os tutores, os conteudistas etc.).

São Paulo foi o estado brasileiro economicamente mais dinâmico no final do século XIX e começo do século XX e, com essa base, capitaneou a industrialização do país, se consolidando como a unidade federativa brasileira mais rica e desenvolvida materialmente. Nesse processo deve se procurar a chave de algumas características estruturantes do sindicalismo dos trabalhadores em educação: o estado administrava uma sólida rede estadual de educação e criou importantes universidades públicas.

Segundo a legislação sindical brasileira não podem existir dois sindicatos representando a mesma categoria num mesmo município. Por um lado isto limita, de acordo ao princípio de unicidade, a pluralidade sindical; mas, por outro lado, coloca no horizonte uma frente de fragmentação sindical: a divisão de sindicatos intermunicipais. Além disso, de acordo com a legislação educacional sancionada na década de 1990, cada prefeitura deve administrar uma rede de escolas. Isto derivou num intenso, diversificado e complexo processo de municipalização do ensino.

Devido a esta dupla situação, é importante considerar a realidade municipal paulista. O estado de São Paulo conta com 645 municípios. Destes, segundo o censo de 2010, 75 tinham mais de 100.000 habitantes. A cidade de São Paulo, capital do estado, é a mais populosa do país, com mais de 12.000.000 de habitantes.

Antes de tratar do sindicalismo na rede estadual paulista, nas redes municipais, na educação superior e na educação privada, cabe contextualizar brevemente o desenvolvimento destas organizações. 


\section{O marco legal e político do sindicalismo dos trabalhadores em educação}

O sindicalismo brasileiro foi reestruturado, pelo Estado, nos primeiros instantes do governo de Getúlio Vargas (1930-45). Algumas características deste modelo sindical foram: a) só considerava a atividade sindical no setor privado, o que fez com que os movimentos trabalhistas do setor público atuassem à margem da legislação, b) não considerava a criação de centrais sindicais, o que também fez com que as centrais sindicais atuassem à margem da legislação c) estrutura sindical com base em sindicatos municipais ou intermunicipais, organizados em federações e finalmente em confederações nacionais, d) unicidade sindical, e) regulação da negociação coletiva, f) controle estatal sobre a criação e o funcionamento dos sindicatos, g) financiamento por meio de contribuições obrigatórias dos trabalhadores representados. Estes elementos não permaneceram invariáveis, mas são chaves para entender o sindicalismo brasileiro contemporâneo.

Na segunda metade da década de 1970, a atividade sindical se intensificou. Destacaram-se setores industriais, o sindicalismo rural, o sindicalismo do setor público e os professores (tanto do setor público como do privado). O impacto desta mobilização sindical foi maior na estrutura sindical do setor público, que justamente era onde - pela falta de regulação estatal da atividade sindical no setor público - as tendências fragmentadoras baseadas nas diferenças políticas, na diferença de titulação, na especialidade ou no nível de ensino no qual se trabalhava se expressavam com mais força.

No estado de São Paulo, depois das greves de metalúrgicos e de professores de 1978, a greve de mais de um mês do conjunto do funcionalismo público estadual, no primeiro semestre de 1979, produziram um singular ciclo de greves que estimulou que as tendências em andamento na base do sindicalismo estadual se expressassem em toda a sua intensidade.

A Constituição Federal de 1988 recolheu demandas sindicais renovadoras, mas manteve alguns dispositivos tradicionais. Por um lado, permitiu a sindicalização dos funcionários públicos; por outro, foi omissa em relação ao direito à negociação coletiva no setor público (que, em linhas gerais, continua sem existir). Anulou com o controle do Ministério de Trabalho sobre os sindicatos, mas manteve a unicidade e a contribuição sindical obrigatória. Isto criou uma situação excessivamente problemática, pois acirrou a disputa intersindical pelo reconhecimento como entidade representativa de determinada categoria (e a obtenção dos recursos que disso se derivam), sem que o governo tivesse capacidade de arbitrar no assunto.

Em 2003 o Supremo Tribunal Federal acabou determinando que o Ministério de Trabalho devesse registrar as entidades sindicais e zelar pelo princípio de unicidade sindical. 
Um setor de lideranças sindicais participou, em 1980, da constituição do Partido dos Trabalhadores (PT). Desta maneira, o PT se diferenciava de uma posição sustentada por outros setores opositores à ditadura, segundo os quais a oposição devia permanecer unida. Os segmentos mais dinâmicos do movimento sindical se reuniram em São Paulo em 1981, na efetivação da Primeira Conferência Nacional da Classe Trabalhadora, que criou uma Comissão Nacional PróCentral Única dos Trabalhadores e, logo em seguida, em 1983, realizaram uma nova conferencia, na qual se decidiu a criação da Central Única dos Trabalhadores (CUT).

Esta segunda conferencia mostrou, além do vigor do movimento, as divisões dentro do sindicalismo, já que importantes sindicatos ficaram fora da CUT. Desde esse momento, pelo menos, existe uma simbiose entre a CUT e o PT, que se se replica no interior da central sindical e do partido: tendencialmente, as divisões e tensões dentro da CUT expressam as divisões dentro do PT e vice-versa.

O fim da ditadura civil-militar e a consolidação do PT como principal organização partidária legalizada de oposição reconfiguraram o cenário político sindical: em 1992 a Corrente Sindical Classista (CSC, com militantes do Partido Comunista do Brasil) ingressou à CUT. Foi criada Força Sindical, a principal concorrente da CUT, com forte peso na indústria, mas limitada presença na educação.

Por muito tempo a filiação à CUT foi uma das definições de políticas sindicais mais discutidas no sindicalismo docente. Alguns sindicatos foram fundadores da central, mas outros grandes sindicatos de trabalhadores em educação (como os do Rio Grande do Sul e do Paraná) se filiaram à central na década de 1990. O sindicalismo em educação se consolidou, salvo raras exceções, como um sindicalismo cutista.

Com a chegada do PT ao governo federal, em 2003, o cenário sindical se reconfigurou. Algumas correntes de esquerda saíram do PT e, junto com militantes do Partido Socialista dos Trabalhadores Unificado (PSTU), integrado por militantes e ativistas sindicais que já tinham saído do PT, passaram a promover a desfiliação da CUT e a criação de novos agrupamentos sindicais, com destaque para a Central Sindical e Popular - CONLUTAS (CSP CONLUTAS).

Em 2007, também, a Corrente Sindical Classista passou a promover a desfiliação da CUT, e criou a Confederação Geral de Trabalhadores e Trabalhadoras do Brasil (CTB).

Além desses grupos, que em linhas gerais participam da tradição sindical cutista, foram criadas a Nova Central Sindical de Trabalhadores (NCST, 2005), a União Geral de Trabalhadores (UGT, 2007) e a Central dos Sindicatos Brasileiros (CSB, 2008). De acordo, com o índice de representatividade do o Ministério de Trabalho, no qual está sub-representado o sindicalismo do 
setor público, em 2014, as principais centrais eram, em ordem decrescente, a CUT (34,39\%), Força Sindical (12,59\%), UGT (11,92\%), NTSC (8,01\%) e CTB (9,33\%).

\section{O sindicalismo da rede estadual de ensino}

O Centro do Professorado Paulista (CPP) foi constituído em 1930 e, por décadas, foi a principal organização de trabalhadores em educação do estado e do país. Reunia professores primários e participou da Confederação dos Professores Primários do Brasil (CPPB) até 1966. (LUGLI, 1997)

Outras entidades foram criadas no âmbito da mesma rede. A Associação dos Professores do Ensino Oficial do Estado de São Paulo (APEOESP), constituída em 1945 como APESNOESP, organizava os professores de ensino médio. (PAULA, 2007) Mas, para a década de 1970 já tinha ampliado, de forma ampla e significativa, o seu quadro associativo e se filiou à Confederação dos Professores Primários do Brasil que, por sua vez, passou a se chamar Confederação dos Professores do Brasil (CPB).

O que estava por trás dessa ampliação, em São Paulo como em escala nacional, era a reestruturação do ensino básico determinado pela lei federal n ${ }^{\circ}$ 5.692/1971, que fixava as diretrizes para o ensino de primeiro e segundo graus. CPP e APEOESP passaram a serem entidades pretensamente concorrentes, mas isto não significou nenhum problema legal nem foi motivo para demandar a intervenção do Estado, porque o sindicalismo legalmente não existia no setor público e, consequentemente, não se aplicava à disputa entre o CPP e a APEOESP a legislação trabalhista que vigorava no país. (GINDIN, 2013)

A União dos Diretores do Ensino Médio Oficial (UDEMO), por sua vez, representava os diretores de escola e se baseava numa particularidade do estado de São Paulo: os cargos de diretores eram providos por meio de concursos, permitindo uma forte identidade profissional nesse segmento de trabalhadores em educação. A UDEMO foi criada em 1952 por um grupo de diretores e vice-diretores que viam ameaçados, justamente, o ingresso exclusivamente por concurso público de provas e títulos à direção das escolas da rede estadual.

A greve icônica dos metalúrgicos da grande São Paulo foi realizada em maio de 1978. Pouco depois, em agosto, os professores da rede pública foram à greve. O Movimento União dos Professores e o Movimento de Oposição Aberto de Professores, que agrupavam a militância que protagonizaria as mobilizações, atuavam como oposição às diferentes direções sindicais - do Sindicato dos Professores de São Paulo (SINPRO São Paulo), do Centro de Professorado Paulista (CPP) e da APEOESP. (FERREIRA JR., 1998) 
O setor que impulsionava a greve instalou o comando de greve na sede de APEOESP, em 1979 ganhou as eleições da entidade e, em 1980, se somou ao movimento que seria decisivo na fundação da CUT. (PAULA, 2007) Em 1981 promoveu a criação de uma nova organização nacional: a União Nacional dos Trabalhadores em Educação (UNATE). A UNATE reunia entidades do setor público e privado, de ensino básico e superior, mas não se consolidou. Ainda neste mesmo ano, a APEOESP voltava à CPB. (FERREIRA JR., 1998)

A APEOESP foi entidade que canalizou a militância sindical do professorado da rede estadual de educação básica. Mas, como mostraremos, foi um processo generalizado. Chama a atenção que os sindicatos de trabalhadores em educação do estado de São Paulo estiveram inicialmente ausentes tanto da coordenação quanto da direção da Comissão Nacional Pró-CUT e, depois, em postos de destaque da direção da CUT ao longo dos anos de 1981, 1983 e 1984.

Isto provavelmente seja uma consequência, por um lado, do peso do sindicalismo industrial paulista na criação da CUT e, por outro, dos alinhamentos políticos dentro da central. De qualquer maneira, foi algo passageiro, pois, na Direção Nacional da CUT eleita em 1986 já há uma liderança da APEOESP (como suplente) e, dois anos depois, essa liderança passou a integrar a Executiva Nacional da central.

O crescimento do sindicalismo dos trabalhadores em educação e as dificuldades que enfrentou o sindicalismo industrial na década seguinte possibilitaram que no ano de 2000, o professor João Felício, dirigente histórico da APEOESP, fosse eleito presidente nacional da CUT. Tratou-se do primeiro presidente desta importante central sindical que não tinha por origem o sindicato de metalúrgicos do ABCD paulista.

A associação de diretores se fortaleceu; e em 1981 foi criada uma nova entidade, de supervisores (APASE, 1981). Os funcionários da educação, no contexto das greves de 1978-79, inicialmente, se organizaram no marco da APEOESP, mas em 1984 criaram a Associação dos Funcionários e Servidores da Educação (AFUSE). Em 1986 a AFUSE decidiu se filiar à CPB. (MIGUEL, 2016) Com a exceção do CPP, todas as entidades da rede estadual paulista se transformaram em sindicatos legalmente reconhecidos depois de 1988.

Neste mesmo período, discutia-se, como em todo Brasil, a criação de sindicatos únicos de trabalhadores em educação. Em 1990 a CPB se reconstituiu como Confederação Nacional dos Trabalhadores em Educação (CNTE), com orientadores, supervisores e funcionários de escola; recomendando que esse caminho fosse trilhado em todos os estados pelas entidades filiadas.

As tentativas de unificar a AFUSE e a APEOESP estavam a todo vapor; e em 1992 AFUSE tomou uma decisão em favor da unificação, enquanto a APEOESP rejeitou essa possibilidade 
(embora não por uma questão programática, mas por questões conjunturais). (MIGUEL, 2016) Atualmente, só em São Paulo e o Distrito Federal há entidades de funcionários, que não se unificaram, filiadas à CNTE.

O CPP continuou crescendo e, em poucas décadas, ultrapassaram os 100.000 sócios, e participou de greves e manifestações. Mas continuou sendo uma organização que não agrupa o ativismo sindical, voltada à prestação de serviços, mormente, jurídicos e assistenciais, e às atividades recreativas e culturais, além do que esse centro de professores não está filiado a nenhuma central sindical.

O atual Sindicato de Especialistas de Educação do Magistério Oficial do Estado de São Paulo foi fundado no dia 18 de outubro de 1952, com a denominação de União dos Diretores do Ensino Médio Oficial (UDEMO); contando com mais de 10.000 sócios, a entidade manteve sua sigla original, sendo muito presente nos movimentos gerais do funcionalismo público, nas campanhas salariais do magistério público paulista e na organização de fóruns preocupados em discutir os rumos e a melhoria da educação brasileira, a UDEMO nunca se filiou a quaisquer centrais sindicais atuantes no país em sua longeva existência.

Além de diretores e vice-diretores, podem se filiar supervisores e professores coordenadores, sendo que uma parte significativa de sócios aposentados. Aliás, o número de diretores aposentados nas escolas públicas paulistas é muito grande. Conforme dados disponibilizados pela Secretaria Estadual de Educação, atualmente, a Rede Estadual de Ensino conta com 2.411 diretores titulares de cargo efetivo (após aprovação em concurso público) e 2.714 diretores designados, sendo necessária a realização de concurso público para preencher 1878 vagas de diretor de escola.

APEOESP cresceu de forma exponencial, passando de 42.438 sócios em 1985 para cerca de 180 mil sócios em fins de 2017; hoje é um dos maiores sindicatos da América Latina, com considerável peso político na CNTE, na CUT e na Internacional de la Educación (IE), que se constitui como uma federação mundial de sindicatos da área educacional.

Na década de 1990 um processo teria um impacto gradual, mas da maior importância nestas organizações: a municipalização da educação básica do setor público. Com efeito, como destacamos, até a década de 1990, a grande protagonista era a rede estadual. Foi no nível fundamental onde cresceu o peso dos municípios: em 1996, 77\% das matrículas do ensino fundamental ainda eram oferecidas pela rede estadual e $12 \%$ pelas redes municipais do estado (MARTINS, 2003); já em 2015, a rede estadual atendia 38\% das matrículas e os municípios o 42\%. 
Se considerarmos o conjunto da educação básica (incluindo os outros níveis), o estado e os municípios tinham, em 2015, praticamente o mesmo peso (38-39\% da matrícula) e o restante 23\% correspondia à rede privada, conforme dados fornecidos pelo Instituto Nacional de Estudos e Pesquisas Educacionais Anísio Teixeira (INEP), em sua Sinopse Estatística da Educação Básica de 2015.

\section{Nota sobre a Afuse}

Como os funcionários de escolas são pouquíssimos estudados ou mencionados nos estudos acadêmicos educacionais, julgamos oportuno, mesmo que, sucintamente, apresentar alguns aspectos de sua história organizativa. Os funcionários da educação iniciaram sua organização filiando-se à Associação dos Professores do Ensino Oficial do Estado de São Paulo (APEOESP), em 1978, reconhecidamente influenciados por uma das maiores greves da história do sindicalismo brasileiro, protagonizada pelos metalúrgicos do chamado ABCD paulista (região constituída por Santo André, São Bernardo, São Caetano do Sul e Diadema, cidades do estado de São Paulo).

Embora instalados na estrutura da APEOESP, até 1984, quando se verificou a necessidade de uma organização que trataria das demandas específicas dos funcionários da educação, surgiu a Comissão Pró-Entidade, provisória nas dependências da Associação dos Professores do Ensino Especialista Municipal (APEEM).

Um simbólico marco de sua estruturação, nesse período, encontra-se na sede da AFUSE: um quadro em sua parede, localizado por nós na visita à sede da entidade. Nele está anexado o seu primeiro boletim com a seguinte frase: “Aqui começou tudo", marcando a realização de sua primeira Assembleia, acontecida em 10 de abril de 1984, ao ocorrer à formação da Comissão Aberta de Funcionários de Escolas e Delegacias, com 186 presentes. (MIGUEL, 2016)

Há que se perceber, pelo teor da mensagem expressa no boletim, a posição tomada pelos seus poucos membros naquele momento, o caráter combativo desde seu início, pelas palavras impressas no seu primeiro boletim dizendo que não só davam integral apoio e colaboração ao movimento dos professores, como também apresentavam suas próprias reivindicações, além de expressar a influência da inflação assustadora.

Deve-se lembrar de que associações e ou sindicatos naquele período enfrentavam as consignas dos militares de plantão, estavam na mira das ações truculentas dos seus interventores, porém os militantes da AFUSE marcaram seus passos na busca da construção de um novo tempo com matrizes democráticas. 
O registro da Associação dos Funcionários e Servidores da Educação do Estado de São Paulo (AFUSE) se deu em 1985. No entanto, somente em 13 de maio de 1989, foi reconhecida pelo Ministério do Trabalho e pela Previdência Social como entidade sindical, conforme apresenta o artigo primeiro do seu estatuto, aprovado; e mais tarde, em 2011, foi adaptado às características atuais.

Foi no fluxo dos grandes acontecimentos e formidável mobilização popular, os quais haveriam de pôr fim à vigência do período ditatorial que, em agosto de 1985, a Comissão PróEntidade organizou e realizou o I Congresso Estadual. Esse momento foi marcante e decisivo na história da entidade, com a participação de cerca de 500 funcionários, tendo por objetivo precípuo estabelecer a fundação da entidade, na ocasião, denominada Associação dos Funcionários e Servidores do Quadro da Secretaria da Educação do Estado de São Paulo (AFSQSESP). Posteriormente foi renomeada como Associação dos Funcionários e Servidores da Educação do Estado de São Paulo ou, simplesmente, AFUSE.

Fruto do incessante trabalho dos seus diretores e ativistas, logo após a sua criação, ainda em 1986, já contava com 8.000 filiados. Em 1986, num contexto de euforia plena e significativo crescimento, foi realizado o seu II Congresso Estadual, oportunidade em que foi tomada importante decisão, nos marcos dos acontecimentos políticos e sociais daquela conjuntura, qual seja, a sua filiação à Confederação Nacional dos Trabalhadores em Educação (CNTE) e à Central Única dos Trabalhadores (CUT). Demarcava, assim, a sua posição de sindicato classista, que haveria de investir na luta por questões abrangentes envolvendo todos os trabalhadores, com dimensão internacionalista e como parte do esforço pela construção de uma fraternidade sem fronteiras.

Também entre os anos de 1986 e 1989, a AFUSE organizou o I e o II Encontro Nacional dos Funcionários da Educação do Brasil, participando da criação da Confederação Nacional dos Trabalhadores em Educação (CNTE).

É importante lembrar que, naqueles dias, estávamos diante de mudanças na denominação da entidade, visto que em 1988 foi aprovada a nova Constituição da República do Brasil, e os funcionários públicos passam a ter direito legal de constituírem seus sindicatos. $\mathrm{Na}$ verdade, os termos Associação e Sindicato guardam diferenças expressivas em suas possibilidades de ações. Este representa política e legalmente uma categoria, independente de ser ou não associada a ele; já aquela não tem competência legal para representação de toda a categoria.

A AFUSE, então, nasceu como associação em 1984 e, em 1989, após a aprovação da Constituição de 1988, pela vontade dos seus sócios, tornou-se sindicato, com o seu 
reconhecimento publicado, no Diário Oficial da União, em 13 de agosto de 1990, transformandose em SINDAFUSE, embora para todos os fins continuasse a usar a sigla anterior.

Nos anos vindouros, a AFUSE cresceu de forma vertiginosa, constituindo um conselho de representantes que haveria de congregar, aproximadamente 500 participantes, incentivou a criação de pelo menos 80 subsedes espalhadas por todas as regiões do estado e congregou 25.000 filiados. (MIGUEL, 2016).

\section{O sindicalismo das redes municipais. $O$ caso da cidade de São Paulo}

O censo escolar do INEP traz alguns obstáculos para os nossos propósitos, mas permite ter uma imagem aproximada da distribuição dos professores municipais no estado de São Paulo. Em 2015, o censo reconhecia em torno de 185.000 professores lecionando nas 645 redes municipais paulistas. Em 559 destes municípios o censo escolar contabilizou menos de 500 docentes; em 86 entre 500 e 1000 e em 32 municípios mais de 1000 docentes. No município de São Paulo atuavam mais de 35.000 docentes. Entre as limitações minimiza a base de representação de um sindicato, porque só contabiliza os professores em sala de aula, no dia do censo. O sindicato também representa trabalhadores de licença, aposentados e, inclusive, pode reunir trabalhadores que atuam em diferentes postos da educação, e não só professores que se encontram na ativa.

Assim como acontece em outros estados (GOUVEIA, 2017), o sindicato estadual, como é caso da APEOESP em São Paulo, oferece suas estruturas sociais e jurídicas e chega mesmo a disputar a adesão dos professores das redes municipais com sindicatos municipais e intermunicipais de professores ou do conjunto do funcionalismo público. É difícil ter um mapa deste complexo universo. Poderia se supor que nas redes maiores atuam sindicatos municipais de trabalhadores em educação e nas redes menores sindicatos municipais ou intermunicipais de funcionários públicos.

Segundo o estatuto da APEOESP (2016), o sindicato atua em 482 redes municipais (75\% do total de 645 redes municipais) e, entre elas, em 25 das redes nas quais, segundo o censo escolar, lecionavam mais de 1000 docentes (78\% das 32). Ou seja, não há uma variação significativa se isolamos do total as redes mais municipais mais importantes. Mas isto não significa muito, porque segundo o estatuto a APEOESP atua na cidade de São Paulo, quando de fato é um ator marginal na gigantesca rede da capital estadual. Pelo seu peso específico, cabe considerar este caso com mais detalhe.

No município de São Paulo atuavam a Associação dos Professores e Especialistas em Educação no Ensino Municipal (APEEM), criada em 1956 e a APROFEM, criada em 1981, inicialmente, congregando professores da zona leste da capital paulista. Ambas ampliaram a base 
de representação (passaram a representar funcionários de escola) e se transformaram em sindicatos no final da década de 1980. A APEEM se transformou no atual SINPEEM. (MATOS, 2010)

Paralelamente à organização dos professores da prefeitura, se consolidava o sindicalismo dos servidores municipais. No caso da prefeitura de São Paulo, se criou o SINDSEP, em 1987, fruto das articulações entre várias associações de funcionários até então atuantes no âmbito dessa municipalidade. Atualmente, o sindicato conta com algo em torno de 25 mil associados e tornouse um sindicato de alta representatividade, inclusive, com expressivo número de filiados entre os trabalhadores que atuam na área de educação.

Assumindo como principais referências políticas organizativas os metalúrgicos de São Bernardo do Campo, os bancários de São Paulo, os professores da rede estadual de ensino (APEOESP), o Sindicato dos Servidores Municipais de São Paulo (SINDSEP), como muitos sindicatos de servidores municipais, está confederado dentro da CUT. Desta maneira se reproduz, em São Paulo, uma disputa nacional pelo enquadramento sindical dos trabalhadores em educação das redes municipais.

Em 1992, quando a prefeitura do Partido dos Trabalhadores avançou com um projeto de que os cargos de especialistas sejam providos por concursos os especialistas não se opuseram, pelo contrário, defenderam o ingresso por concurso, e criaram o Sindicato dos Especialistas de Educação do Ensino Público Municipal de São Paulo (SINESP).

O SINESP ocupa o lugar que na rede estadual tem a UDEMO e a APASE, na medida em que acolhe a filiação de diferentes segmentos de profissionais que atuam no quadro do magistério público paulistano. Finalmente, os trabalhadores das creches municipais, um segmento em expansão e com identidade própria, criaram primeiro uma associação e, em 2004, um sindicato: o Sindicato da Educação Infantil (SEDIN), que representa uma base de 25 mil trabalhadores da educação no município de São Paulo. (BANDEIRA \& BAUER, 2020)

A principal organização, o SINPEEM, cresceu de 3.600 para 34.000 sócios entre 1989 e 1999. É filiada à CNTE e à CUT. As organizações de especialistas e professores de educação infantil, assim como a APROFEM, não estão filiadas a nenhuma central sindical. (SADI, 2001)

\section{O sindicalismo em educação do setor privado}

Na década de 1940 já existiam sindicatos de professores legalmente reconhecidos, na educação privada, nas cidades de São Paulo, Campinas e Santos. Em 1951, junto com os Sindicatos dos Auxiliares de Administração Escolar de São Paulo e de Campinas, constituíram a Federação dos Trabalhadores em Estabelecimentos de Ensino do Estado de São Paulo (FETEE/SP). 
A FETEE participou da criação da Confederação Nacional dos Trabalhadores em Estabelecimentos de Educação e Cultura, em 1966, no estado de São Paulo - tudo no marco da estrutura sindical oficial.

A mobilização dos finais da década de 1970 atravessou também o sindicalismo do setor privado, onde pôde se sentir o impacto da militância vigorosa da APEOESP. Impacto bastante direto, pela existência de muitos professores com dois vínculos. O SINPRO de Osasco, por exemplo, criado na década de 1980, compartilhou inicialmente a sede e realizou algumas importantes campanhas políticas pela redemocratização doa país com a APEOESP. (BANDEIRA, 2015)

Nas grandes cidades de São Paulo e Campinas apareceu um novo segmento militante: professores das universidades católicas - o setor privado tradicional no ensino superior. A Associação dos Professores da Pontifícia Universidade Católica de São Paulo (APROPUC) foi criada em 1976 (MATHIAS, 2015) e, na PUC-Campinas, em 1978, surgiu a APROPUCC. Enquanto esta última se envolveu na disputa pela direção do SINPRO Campinas, os professores da Pontifícia Universidade Católica de São Paulo embora se identificassem com o chamado novo sindicalismo, militassem em torno das fileiras da CUT, tendo, inclusive, participado do processo de criação da ANDES, objetivamente, se furtaram de quaisquer filiações sindicais e ficaram no olho da disputa entre os SINPROS e o ANDES, relacionando-se, esporadicamente, com ambos.

Novos sindicatos foram organizados, alguns representando não só aos professores, mas também aos auxiliares. Em outros casos o sindicato de professores ampliou a sua base de representação para representar os auxiliares. Aparentemente, nas cidades maiores, que foram as primeiras a se organizar sindicalmente, é onde este processo não avançou e ainda funcionam sindicatos separados (este é atualmente o caso de Guarulhos, Campinas, Osasco, Campinas, São Paulo).

A ruptura de 1988, com a nova constituição, tiveram impactos diretos no mapa sindical na estruturação das federações e confederações: alguns dos novos sindicatos, os de Osasco e região e o do ABC, confluíram com os SINPROs de São Paulo, Campinas e Santos para criar uma nova federação estadual, a Federação dos Professores do Estado de São Paulo (FEPESP). Este setor participou em 1991 da constituição de uma nova confederação, a Confederação Nacional dos Trabalhadores em Estabelecimentos de Ensino (CONTEE). A FEPESP e a CONTEE se filiaram à CUT.

O processo de criação de novos sindicatos continuou, a partir dos municípios nos quais não atuava nenhum sindicato reconhecido pelo Ministério ou da divisão de sindicatos de alguns 
grandes sindicatos. Com base em dados coletados, em fins de 2017, por exemplo, o SINPRO de Bauru e o SINTEE de Presidente Prudente atuam em mais de 40 municípios. O SINPRO de Guarulhos e o SINPROVALES foram cridos em 2001. Sindicatos organizados no marco da federação tradicional, a FETEE, foram se desfiliando e migrando à FEPESP, entre eles o sindicato de Sorocaba, em 2008, e o da França, em 2010.

A FETEE/SP continua se organizando na CNTEEC e se filiou à Central dos Sindicatos Brasileiros (CSB), uma central constituída no âmbito da reorganização das centrais sindicais, sem peso nos setores importantes do movimento. A federação reúne 10 sindicatos e atua também como representante dos trabalhadores do que se denomina "área inorganizada" - ou seja, das cidades nas quais não atua um sindicato reconhecido pelo Ministério. A FEPESP reúne atualmente 25 sindicatos, a maioria deles intermunicipais.

Entre essas, podemos mencionar as seguintes entidades: Sindicato dos Professores de Indaiatuba, Salto, Itu - Sinpro Vales, Sindicato dos Professores de Taubaté e Região - Sinpro Taubaté e Região, Sindicato dos Professores de São Paulo - Sinpro São Paulo, Sindicato dos Trabalhadores em Estabelecimentos de Ensino e Educação de São Carlos e Região-Sinpro São Carlos, Sindicato dos Auxiliares de Administração Escolar de São José do Rio Preto e região, Sindicato dos Professores e Auxiliares de Administração Escolar de Ribeirão Preto - Sinpaae Ribeirão Preto e Região, Sindicato dos Trabalhadores em Estabelecimentos de Ensino de Presidente Prudente - Sintee Presidente Prudente e Região, Sindicato dos Professores de Osasco e Região - Sinpro Osasco e Região, Sindicato dos Trabalhadores em Estabelecimentos de Ensino e Educação de Franca - Sinteee Franca, Sindicato dos Professores de Bauru - Sinpro Bauru e Região, Sindicato dos Professores do ABC - SINPRO-ABC, Sindicato dos Professores de Sorocaba e Região, Sindicato dos Professores de Santos, Sindicato dos Professores e Professoras de Guarulhos, Sindicato dos Professores de Campinas - SINPRO.

No final da década de 1980, os sindicatos de auxiliares criaram uma federação específica, a Federação Paulista de Auxiliares em Administração Escolar (FEPAAE). Mas esta ficou inativa até que, em 2007, foi reativada. Nesta federação estão atualmente reunidos 17 sindicatos; alguns só de auxiliares, que é a principal base da federação (os de São Paulo, ABC, Campinas, Guarulhos, Osasco, Santos); três sindicatos de professores e quatro sindicatos que organizam auxiliares e professores. A FEPAAE, como a FETEE com os professores, representa a escala estadual a "base inorganizada" dos auxiliares de ensino do setor privado. Um dado importante: a FEPAAE também negocia as condições de trabalho dos professores dos sindicatos da sua base. 
Os sindicatos de professores também atuam no "Sistema S" (instituições independentes do Estado, mas que com recursos garantidos por lei, com gravitação na área da educação profissional) e num segmento que teve uma expansão impressionante: o ensino superior oferecido pelas empresas educacionais. (SOUSA, 2015) No ensino superior privado, em São Paulo, em fins de 2017, trabalhavam 60.500 pessoas, ocupando posições técnicas e administrativas, ao lado de 63.500 docentes. O número mais do que duplica a quantidade de docentes que trabalha no setor público no ensino superior.

Há também docentes municipais e dos Institutos e Centros de Educação técnica. O sistema de ensino superior brasileiro diferencia universidades, centros universitários e faculdades. De acordo com os dados da Sinopse estatística da educação básica de 2015, em 26 municípios as redes privadas empregavam entre 500 e 1000 professores, e em 20 mais de 1.000. No município de São Paulo a rede privada empregava mais de 55.000 professores de educação básica. Lembrando-se que este estudo expressa uma sub-representação da base de um sindicato, porque só contabiliza os professores em sala de aula, no dia do censo. Neste caso a população está ainda mais subvalorada do que quando se considera o setor público, pois os sindicatos do setor privado normalmente atuam também na educação superior e no sistema $\mathrm{S}$.

Neste caso pode se fazer com mais consistência uma relação entre o tamanho da rede e o mapa sindical. A FEPESP representa 13 das 26 (50\%) redes nas quais atuavam entre 500 e 1000 docentes na educação básica de acordo com o censo escolar de 2015; e 18 das 20 (90\%) redes mais de 1000 docentes, segundo a mesma fonte. A FETEE filia seis sindicatos de municípios que, segundo o censo escolar, tinham entre 500 e 1000 docentes na educação básica, há um sindicato independente com bases importantes (o de Mogi das Cruzes e região) e outra grande rede de professores representada pela FEPAAE (a de São José dos Campos).

Em 2011 a FEPESP se desfiliou da CUT, fundamentalmente por pressão das lideranças identificadas com a CTB, central à qual estão filiados alguns sindicatos da FEPESP (Campinas, Sorocaba), mas nessa demanda confluíram com os filiados à CONLUTAS (SINPRO Guarulhos). Também o SINPRO São Paulo e, em 2012, a confederação nacional, saíram da CUT.

\section{O sindicalismo das universidades públicas}

Uma particularidade do estado de São Paulo é a existência de uma rede de universidades estaduais com particular força; à tradicional Universidade de São Paulo (USP) se somaram a Universidade de Campinas (UNICAMP) na década de 1960 e a Universidade Estadual Paulista "Júlio de Mesquita Filho" (UNESP) na década seguinte. A rede federal tem um peso relativamente 
menor, sendo integrada pela Universidade Federal de São Carlos (criada na década de 1960), a Universidade Federal de São Paulo (década de 1990) e a Universidade Federal do ABC (UFABC, anos 2000).

Na USP atuava, desde a década de 1950, um agrupamento denominado Associação dos Auxiliares de Ensino, que representava aos professores não catedráticos. A reforma universitária de 1968 reconfigurou a organização do ensino superior, acabando com essa segmentação dentro dos professores universitários.

Neste contexto, em 1976, foi constituída a Associação dos Docentes da Universidade de São Paulo (ADUSP) e a Associação dos Docentes da Unesp (Adunesp) - Seção sindical do ANDES - Sindicato Nacional, que representa os docentes e pesquisadores vinculados à Universidade Estadual Paulista "Júlio de Mesquita Filho".

Logo em seguida, em 1977, foi Fundada a Associação dos Docentes da Unicamp (Adunicamp) - Seção sindical do ANDES - Sindicato Nacional, com o intuito de representar os professores que atuam na Universidade Estadual de Campinas (Unicamp).

Originalmente, em $1^{\circ}$ de fevereiro de 1978, constituída como Associação de docentes da Universidade Federal de São Carlos (ADUFSCar), posteriormente, em 08 de dezembro de 2016, requereu o seu registro oficial com a denominação de Sindicato dos Docentes em Instituições Federais de Ensino Superior dos Municípios de São Carlos, Araras e Sorocaba (ADUFSCar Sindicato).

Note-se que em dois anos todas as universidades públicas tinham associações de professores. Estas estavam à frente da organização nacional da categoria: em 1981, na cidade de Campinas, foi criada a Associação Nacional dos Docentes do Ensino Superior (ANDES).

Em 1988 o ANDES se converteu em Sindicato Nacional dos Docentes das Instituições de Ensino Superior (o ANDES-SN). As associações locais se transformaram em "seções" de um sindicato nacional. Esse mesmo ano o ANDES filiou-se à CUT.

Os trabalhadores técnico-administrativos se organizaram paralelamente e não esteve na pauta, pelo menos com destaque, a unificação com as organizações de professores. A Associação dos Servidores da Universidade de São Paulo (ASUSP), criada na década de 1960 e com fins assistenciais, passou a ser dirigida pelos setores emergentes identificados com o novo sindicalismo em 1979, potencializando a criação do Sindicato dos trabalhadores da Universidade de São Paulo (SINTUSP). (DINIZ, 2017)

Nos outros casos se tratava de entidades novas. Este segmento organizou uma federação nacional própria em 1978 - a Federação das Associações de Servidores das Universidades 
Brasileiras (FASUBRA). Em 1986 FASUBRA se filiou à CUT (isto é, dois anos antes que o sindicato nacional de professores universitários).

Quando comparado com o sindicalismo da educação básica do setor público e com o sindicalismo do setor privado, pode se ver que o sindicalismo das universidades públicas construiu - embora dividido entre professores e servidores - um movimento relativamente mais homogêneo em termos político-sindicais. Isto em parte se deve à inexistência de grandes organizações tradicionais (como o CPP na rede estadual), à falta de uma legislação que promova sindicatos quase sem militância (como é o caso de alguns sindicatos da rede privada) e à existência de um pequeno grupo de grandes empregadores (o que não acontece na educação básica). Para inicios da década de 1990 existia só um sindicato de professores universitários e um sindicato de servidores por universidade, todos organizados na Central Única dos Trabalhadores (CUT).

Em meados de 2017, quase 26.000 docentes atuam no ensino superior público em São Paulo. Os principais segmentos são os das universidades estaduais (aproximadamente 12.500), distribuídos, conforme dados de 2016, da seguinte forma: USP, 5.978; UNESP, 3.631; Unicamp, 1.867 docentes e das universidades federais em torno de 3.500. Nesses segmentos trabalham, respectivamente, $28.500,3.500$ e 5.500 servidores técnicos. Os sindicatos dos servidores e os sindicatos de professores das três universidades estaduais, que é o principal segmento, atuam conjuntamente no âmbito do Fórum das Seis.

Nesse universo aparece também a Faculdade de Tecnologia de São Paulo (FATEC-SP), criada em 10 de abril de 1973, vinculada ao Centro Estadual de Educação Tecnológica Paula Souza, conta um quadro estável de 277 professores, 160 funcionários e um número significativo de trabalhadores que atuam de forma instável e precária. Esses são representados pela Associação dos Docentes das Faculdades de Tecnologia (ADFATEC), que mantém estreita relações com a ADUNESP e o Andes-SN.

Mas a unidade política do sindicalismo do ensino superior do setor público foi desafiada pela realidade política durante a emergência dos conflitos causados pela chegada do PT governo federal. Um grupo de entidades deixou a CUT, para se filiar à Central Sindical e Popular Conlutas (CSP CONLUTAS). Este foi o caminho das entidades nacionais, ANDES e FASUBRA. Por outro lado, a Associação de Docentes da UFSCAR decidiu sair do ANDES, se constituir em sindicato, e participou da criação da PROIFES-Federação, uma federação filiada à CUT que disputa a representação do setor com o ANDES. 
Filiação atual dos sindicatos das universidades públicas

Tabela 1 - Quadro elaborado pelos autores

\begin{tabular}{|c|c|c|}
\hline Sindicato & Federação & Central \\
\hline $\begin{array}{l}\text { USP Professores } \\
\text { Associação de Docentes da } \\
\text { USP (Adusp) }\end{array}$ & $\begin{array}{l}\text { ANDES [Sindicato Nacional dos } \\
\text { Docentes das Instituições de } \\
\text { Ensino Superior (ANDES-SN)]. }\end{array}$ & $\begin{array}{l}\text { CONLUTAS [CSP Conlutas - } \\
\text { Central Sindical e Popular }]\end{array}$ \\
\hline $\begin{array}{l}\text { USP Servidores } \\
\text { Sindicato dos Trabalhadores da } \\
\text { USP (Sintusp) }\end{array}$ & & CONLUTAS \\
\hline $\begin{array}{l}\text { UNICAMP Professores } \\
\text { Associação dos Docentes da } \\
\text { Universidade Estadual de } \\
\text { Campinas (Adunicamp) }\end{array}$ & ANDES & CONLUTAS \\
\hline $\begin{array}{l}\text { UNICAMP Servidores } \\
\text { Sindicato dos Trabalhadores da } \\
\text { Unicamp (STU) }\end{array}$ & $\begin{array}{l}\text { FASUBRA [Federação das } \\
\text { Associações de Trabalhadores (as) } \\
\text { das Universidades Brasileiras] }\end{array}$ & \\
\hline UNESP Professores & ANDES & CONLUTAS \\
\hline $\begin{array}{l}\text { UNESP Servidores } \\
\text { Sindicato dos Trabalhadores } \\
\text { da Unesp (Sintunesp) }\end{array}$ & & \\
\hline UFSCAR Professores & $\begin{array}{l}\text { PROIFES [Federação de Sindicatos } \\
\text { de Professores e Professoras de } \\
\text { Instituição Federais de Ensino } \\
\text { Superior e de Ensino Básico } \\
\text { Técnico e Tecnológico (PROIFES)] }\end{array}$ & $\begin{array}{l}\text { O PROIFES não é formalmente } \\
\text { filiado à CUT, mas, se coloca como } \\
\text { "parceiro" desta central, como } \\
\text { também com a CNTE. }\end{array}$ \\
\hline $\begin{array}{l}\text { UFSCAR Servidores } \\
\text { Sindicato dos Trabalhadores } \\
\text { Técnicos-Administrativos da } \\
\text { UFSCar (SINTUFSCar) }\end{array}$ & FASUBRA & CONLUTAS \\
\hline $\begin{array}{l}\text { UNIFESP Professores } \\
\text { Associação dos Docentes da } \\
\text { Universidade Federal de São Paulo } \\
\text { - Seção Sindical do ANDES-SN }\end{array}$ & ANDES & CONLUTAS \\
\hline $\begin{array}{l}\text { UNIFESP Servidores } \\
\text { Sindicato dos Trabalhadores da } \\
\text { Universidade Federal de São Paulo } \\
\text { (Sintunifesp) }\end{array}$ & FASUBRA & CONLUTAS \\
\hline $\begin{array}{l}\text { UFABC Professores } \\
\text { Associação dos Docentes da } \\
\text { Universidade Federal do ABC } \\
\text { (ADUFABC), - Seção Sindical do } \\
\text { ANDES-SN }\end{array}$ & ANDES & CONLUTAS \\
\hline $\begin{array}{l}\text { UFABC Servidores } \\
\text { Sindicato dos Trabalhadores das } \\
\text { Universidades Federais do ABC }\end{array}$ & FASUBRA & CONLUTAS \\
\hline
\end{tabular}

\section{Fonte: xxx}




\section{Considerações finais}

Os organismos sindicais e associativistas servem para aglutinar e defender os interesses da categoria e organizá-la para conquistas coletivas em defesa de seus direitos históricos e necessidades imediatas. Mas, então, como explicar tamanha pulverização que se registra entre aqueles que vivem do próprio trabalho no mundo da educação?

A convivência entre os trabalhadores da educação das instituições públicas e privadas paulistas, até o presente momento histórico, numa mesma entidade que os representassem, não foi possível de se constituir política e socialmente. Mesmo nos anos das agudíssimas mobilizações sindicais e políticas, dos fins da década de 1970 e dos inícios dos anos 1980, que trouxeram para a cena política nacional a presença da Central Única dos Trabalhadores (CUT) e a unidade entre os trabalhadores se mostrava imperiosa para impor a derrocada da ditadura militar, isso não aconteceu.

Os processos de ampliação da representação existiram, e significaram em vários casos que os mesmos sindicatos representassem auxiliares e professores. Um fenômeno ainda mais profundo, e de escala nacional, é a unificação das associações de professores das universidades públicos num sindicato nacional.

A principal causa do aumento da quantidade de sindicatos, no setor privado, tem sido desde a década de 1980 a criação de novos sindicatos. Não parece ter havido divisão dentro da categoria, e a muitos SINPROs nucleiam uma base relativamente heterogênea. Mas tem se multiplicado. Porque os SINPROs existentes, na década de 1980, simplesmente não ampliaram a sua base de representação? Quão estendida foi à divisão de SINPROs? Trata-se de um fenômeno que exige uma resposta dos pesquisadores da área.

No caso do setor público, o sindicalismo das redes municipais paulistas ainda é, em certa medida, uma "caixa preta". Neste caso, o grande potencializador da fragmentação sindical foi à própria municipalização.

Uma particularidade de São Paulo - e que se expressa também na capital do estado - é a fragmentação "vertical" da categoria. Como destacamos, a origem deve se procurar no fato de que a rede estadual estava consolidada e o ingresso dos diferentes profissionais se realizava por concursos específicos. Isto dava uma forte identidade a cada segmento. Aqui, o fato mais importante é que o novo sindicalismo não conseguiu, nem com toda a força da identidade de trabalhadores em educação, quebrar esta tradição.

$\mathrm{Na}$ educação básica, pode se reconhecer uma confluência entre professores e "auxiliares" ou "servidores" (ou seja, entre os trabalhadores com e sem formação docente do setor 
educacional). É interessante porque isto aconteceu tanto no setor público como no privado, e nos dois casos com ambiguidades. Nada disto é visível no ensino superior.

Nem todas as associações se transformaram em sindicatos: não o fez o CPP.

O mapa político atual dos sindicatos de trabalhadores em educação expressa indefinições e a trajetória das diferentes correntes do que foi o velho sindicalismo cutista, hoje dividido. No sindicalismo do setor privado se evidencia um forte peso dos militantes do PT e do PCdoB, tensão que explica a saída da CUT da federação paulista e do principal sindicato nacional do país.

$\mathrm{Na}$ educação básica do setor público, a hegemonia é do PT, embora na realidade menos incontestável do que parece quando se olha a filiação das principais organizações. As principais entidades do ensino superior público são lideradas pela ex-esquerda cutista, hoje identificada fundamentalmente com a Central Sindical e Popular Conlutas (CSP CONLUTAS).

Embora seja difícil reconstruir a situação das redes municipais, no setor privado este arco de organizações cresceu constantemente, a expensas das tradicionais organizações do setor. Não há indícios de incidência no setor nem da Força Sindical nem a União Geral de Trabalhadores (UGT) - que são as que com mais efetividade concorreram com a CUT no sindicalismo do setor privado.

Por fim é importante dizer que o presente estudo se coloca com o objetivo de contribuir com o mapeamento e o fornecimento de informações elementares e basilares com o intuito de subsidiar os interessados no desenvolvimento de estudos sobre a história imediata ou do tempo das associações e dos sindicatos dos trabalhadores em educação, procurando estimular o fortalecimento desta temática no debate historiográfico educacional.

O levantamento e a articulação dos dados próprios do tempo presente e da história imediata do associativismo e do sindicalismo dos trabalhadores em educação do estado de São Paulo nos mostra o alcance social de uma forma de organização complexa que envolve amplos setores de trabalhadores que atuam em instituições públicas e privadas, comunitárias e confessionais, nos oferece, ainda, condições de discutir os seus mais sentidos problemas, o desenvolvimento de sua consciência profissional, a compreensão das relações de trabalho, como estas são afetadas pelas políticas educacionais, as possibilidades de resistência, a afirmação dos seus direitos e o reconhecimento de sua importância política e social. 


\section{Referências}

APEOESP, Estatuto da APEOESP, São Paulo, 2016.

BANDEIRA, Maria Crisneilândia. História, embates políticos, sindicais e organizativos dos professores das instituições do ensino privado de Osasco e Região (SINPROSASCO) (19851992). Dissertação de Mestrado em Educação, Universidade Nove de Julho, 2015.

BANDEIRA, Maria C. \& BAUER, Carlos. História da luta pela educação infantil na cidade de São Paulo (1970-1980). São Paulo: Amazon \& Independently published, 2020.

BRASIL. INSTITUTO NACIONAL DE ESTUDOS E PESQUISAS EDUCACIONAIS Anísio Teixeira, Sinopse Estatística da Educação Básica 2015 (on line), Brasília, INEP, 2016.

DINIZ, Cássio. Da invisibilidade à conquista do espaço social: história concisa das lutas políticas e sindicais dos trabalhadores em educação da Universidade de São Paulo (1978-1988). Tese de Doutorado em Educação, Universidade Nove de Julho, São Paulo, 2017.

FERREIRA JR., Amarilio. Sindicalismo e proletarização: a saga dos professores brasileiros. Tese de Doutorado em História Social, Universidade de São Paulo, São Paulo, 1998.

GINDIN, Julián, "Sindicalismo dos trabalhadores em Educação: tendências políticas e organizacionais (1978-2011)", Educar em Revista n. 48, Curitiba, abr./jun, 2013.

GOUVEIA, Andréa Barbosa, "La organización sindical de los docentes en los municipios del Estado de Paraná: un mapa preliminar”, Polifonias n. 10, Departamento de Educación Universidad de Luján, 2017.

LUGLI, Rosário Genta. Um estudo sobre o CPP (Centro do Professorado Paulista) e o movimento de organização dos professores (1964-1990). Dissertação de Mestrado em Educação, Universidade de São Paulo, São Paulo, 1997.

MATOS, Alessandro Rubens de. A trajetória do Sindicato dos Profissionais em Educação no Ensino Municipal (SINPEEM): 1988-2004. Dissertação de Mestrado em Educação, Universidade Nove de Julho, São Paulo, 2010.

MARTINS, Ângela Maria, Um analise da municipalização do ensino no estado de São Paulo, Cadernos de Pesquisa n. 120, novembro 2003.

MATHIAS, Emerson Feliciano. História da gênese e consolidação política da Associação dos professores da Pontifícia Universidade Católica de São Paulo - APROPUC (1976-1985). Dissertação de Mestrado em Educação, Universidade Nove de Julho, São Paulo, 2015.

MIGUEL, Miriam Maria Bernardi. História da educação brasileira e seus personagens invisíveis: práticas sindicais e políticas do Sindicato dos funcionários e servidores da educação do Estado de São Paulo - Afuse (1978-1992). Tese de Doutorado em Educação, Universidade Nove de Julho, São Paulo, 2016. 
BAUER, Carlos; GINDIN, Julián. Rudimentos históricos do associativismo e do sindicalismo dos trabalhadores em educação no Estado de São Paulo (1978-2017)

PAULA, Ricardo Pires de. Entre o sacerdócio e a contestação: uma história da APEOESP (19451989). Tese de Doutorado em História, Universidade Estadual Paulista, Marília, 2007.

SADI, Renato Sampaio. Projeto das direções sindicais da educação de São Paulo-SP. Tese (Doutorado em Educação) - Pontifícia Universidade Católica de São Paulo, São Paulo, 2001.

SOUSA, Andréa Luciana Harada. Mercantilizão da educação e precarização das relações de trabalho docente: o ensino superior privado e a atuação do Sindicato de Professores e Professoras de Guarulhos. Dissertação de mestrado em Educação, Universidade Estadual de Campinas, Campinas, 2015. 